\title{
Evolution of Norms in the Emergence of Digital Business Ecosystems
}

\author{
Prince Kwame Senyo ${ }^{1,2(\bowtie)}$, Kecheng Liu ${ }^{2,4}$, Lily Sun ${ }^{3}$, \\ and John Effah ${ }^{1}$ \\ ${ }^{1}$ Department of Operations and Management Information Systems, \\ University of Ghana, Accra, Ghana \\ \{pksenyo, jeffah\}@ug.edu.gh \\ ${ }^{2}$ Henley Business School, Informatics Research Centre, \\ University of Reading, Reading, UK \\ k.liu@henley.ac.uk \\ ${ }^{3}$ School of Systems Engineering, University of Reading, Reading, UK \\ lily.sun@reading.ac.uk \\ ${ }^{4}$ School of Information Management and Engineering, \\ Shanghai University of Finance and Economics, Shanghai, China
}

\begin{abstract}
As digital business ecosystems emerge from traditional business ecosystems, norms evolve or remain. However, less is known about evolution of norms in relation to digital business ecosystems. Norms are rules that govern behaviour; as such they drive activities in business ecosystems. Therefore, this paper uses Ghana's import-export ecosystem to trace the evolution of norms when traditional business ecosystems transition to digital business ecosystem in order to understand which norms change or remain and the reasons that account for the changes.
\end{abstract}

Keywords: Digital business ecosystem - Business Ecosystem - Norms · Organisational semiotics $\cdot$ Import-export ecosystem

\section{Introduction}

Business Ecosystem (BE) is a network of interdependent organisations with shared goals to co-create [1] value. BE can be traditional or digital. While interactions in traditional BEs (TBEs) rely on direct business to business communication, that of digital business ecosystems (DBEs) is based on an integrated dynamic organisational network supported by the Internet [2]. As DBEs emerge from TBEs, norms may evolve or remain. Norms are rules or standards that guide activities [3]. Hence, their evolution when TBEs transition to DBEs is an important phenomenon for information systems and organisational research.

Even though BE have witnessed some studies (e.g., [2, 4-6]) in information systems research, less attention has been paid to evolution of norms. Therefore, this study contributes to $\mathrm{BE}$ research by investigating how norms evolve when DBEs emerge 
from TBEs. The rest of this paper is organised as follows. Section 2 discusses related works on TBE and DBE. Section 3 presents organisational semiotics models, namely organisational onion and morphology as theoretical lenses for this study. Section 4 presents a case study of Ghana's import-export ecosystem to demonstrate emergence of a DBE from a TBE and how norms evolve or remain after the transition. Section 5 concludes the paper and presents directions for future research.

\section{Related Works}

\subsection{Traditional Business Ecosystem}

The traditional use of the term BE [7] describes interdependency among organisations in a network. BE is analogous to biological ecosystem [1]. However, one feature that distinguishes $\mathrm{BE}$ from its biological counterpart is the shared goal of value co-creation, which is beyond the scope and capabilities of individual partners. As a network of organisations, TBEs need to be guided by norms that regulate the behaviour of partners. The interactions among partners in TBEs are mostly direct organisation to organisation communication without centrality of the Internet [8]. However, with the emergence of the Internet, some TBEs have evolved into DBEs [2].

\subsection{Digital Business Ecosystem}

DBE is an organisational network that enables digital collaboration [2]. However, the main distinguishing feature of DBE from TBE is the centrality of digital network infrastructure in the interaction of its partners. Following the transition of some TBEs to DBEs, much focus of related research has been on architecture redesign [2, 8], new areas of practical application [4] and regulatory issues [9]. For example, Razavi et al. [8] investigate the evolution of TBEs to DBEs and focused on how static TBE hubs are converted to dynamic DBE hubs. However, evolution of norms in the emergence of DBE from TBE is yet to receive the necessary attention in information systems and organisational research. This study therefore focuses on evolution of norms when DBEs emerge from TBEs.

\section{Organisational Semiotics}

Organisational semiotics is a branch of semiotics that studies organisations as information systems made up of collection of signs. A sign itself is anything that stands for something to someone $[3,10]$. Creation and use of signs are subject to norms as rules or standards that shape organisational activities. This study draws on two organisational semiotics models; the organisational onion and the organisational morphology, to analyse the evolution of norms when TBEs transition to DBEs. 


\subsection{Organisational Onion}

The organisational onion categorises norms into informal, formal and technical [10] as shown in Fig. 1. Informal norms represent unstructured and undocumented rules or standards. On the other hand, formal norms are documented bureaucratic rule or standards. Technical norms represent formal norms that have been digitized [3]. Both the informal and formal norms are carried out in the physical domain while technical norms are carried out within the digital domain [11]. This study draws on the organisational onion to analyse evolution of informal, formal and technical norms as TBEs transition to DBEs.

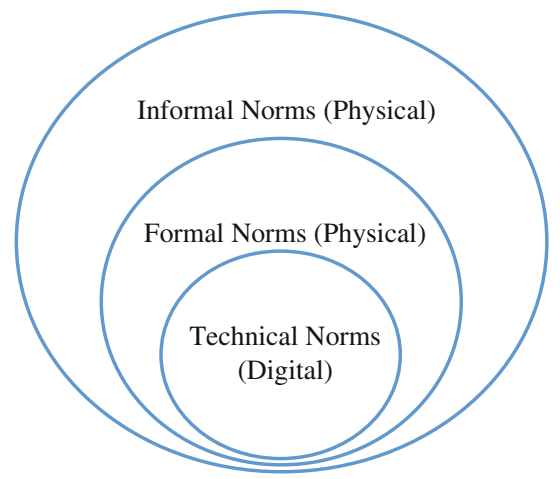

Fig. 1. Organisational onion [11]

\subsection{Organisational Morphology}

Organisational morphology (Fig. 2) classifies behavioural norms into substantive, communication and control norms [3]. First, substantive norms define core activities of organisations. Second, communication norms concern exchange of information among organisational actors. Third, control norms monitor and regulate substantive as well as communication norms. This study draws on the organisational morphology to analyse norm evolution from physical to digital domains in terms of substantive, communication and control norms.

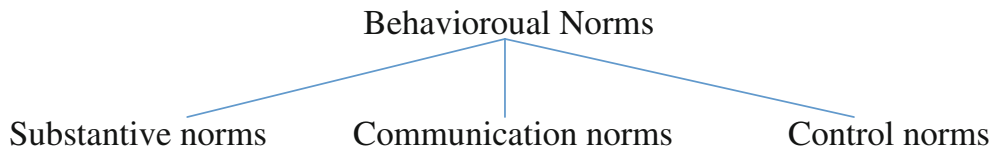

Fig. 2. Organisational morphology [3] 


\section{Evolution of Ghana's Import-Export Digital Ecosystem}

This section presents the case of the transition of Ghana's import-export ecosystem to DBE. Given the complexity of the whole import-export system, the current focus of this paper is on the import ecosystem, which is used to illustrate norm evolution from TBE to DBE.

\subsection{The Import Traditional Business Ecosystem}

Until 2000, the import ecosystem was traditional. The members included importers, shipping lines, Customs, banks, logistics companies, Ministry of Trade and Industry (MOTI), Destination Inspection Companies (DICs) and the Ghana Port and Harbour Authority. The norms that guided activities in the TBE were physical. Table 1 shows the behavioural norms and their types.

Table 1. Norms under the import traditional business ecosystem

\begin{tabular}{|c|c|c|}
\hline Norm \# & Norm definition & Norm type \\
\hline $\mathrm{T} 1$ & $\begin{array}{l}\text { An importer was required to purchase import declaration form } \\
\text { (IDF) from MOTI }\end{array}$ & Substantive \\
\hline $\mathrm{T} 2$ & $\begin{array}{l}\text { An importer was required to submit completed IDF to a DIC for } \\
\text { valuation }\end{array}$ & Communication \\
\hline $\mathrm{T} 3$ & $\begin{array}{l}\text { A DIC was required to send Final Classification and Valuation } \\
\text { Report (FCVR) to the importer }\end{array}$ & Communication \\
\hline $\mathrm{T} 4$ & $\begin{array}{l}\text { An importer was required to purchase Customs import declaration } \\
\text { form }\end{array}$ & Substantive \\
\hline T5 & $\begin{array}{l}\text { An importer was required to complete and submit Customs import } \\
\text { declaration form and FCVR, shipping manifest as well as bill of } \\
\text { lading to Customs }\end{array}$ & Communication \\
\hline T6 & $\begin{array}{l}\text { Customs was required to review, verify and validate documents } \\
\text { submitted by an importer }\end{array}$ & Control \\
\hline $\mathrm{T} 7$ & $\begin{array}{l}\text { Customs was required to send review and verification report to the } \\
\text { importer }\end{array}$ & Communication \\
\hline $\mathrm{T} 8$ & An import was required to pay import duties at the bank & Substantive \\
\hline T9 & The bank was required to notify Customs of payment & Communication \\
\hline $\mathrm{T} 10$ & $\begin{array}{l}\text { A Customs official was required to physically examine } \\
\text { consignment }\end{array}$ & Control \\
\hline $\mathrm{T} 11$ & $\begin{array}{l}\text { Consignment was required to be released after physical } \\
\text { examination }\end{array}$ & Substantive \\
\hline
\end{tabular}

\subsection{The Import Digital Business Ecosystem}

In 2000, the import ecosystem transitioned from TBE to DBE. As a result, an electronic integrated digital platform was deployed. Table 2 shows the behavioural norms, types and domain under the emerged DBE. 
Table 2. Norms under the import digital business ecosystem

\begin{tabular}{|c|c|c|c|}
\hline Norm \# & Norm definition & Norm type & Domain \\
\hline D1 & An importer is required to purchase IDF from MOTI & Substantive & Physical \\
\hline $\mathrm{D} 2$ & An importer is required to submit the IDF to a DIC & Communication & Physical \\
\hline D3 & A DIC is required to send FCVR to the importer & Communication & Physical \\
\hline D4 & $\begin{array}{l}\text { An importer must complete Customs import declaration form on the } \\
\text { digital platform }\end{array}$ & Communication & Digital \\
\hline D5 & $\begin{array}{l}\text { An importer must submit FCVR, shipping manifest and bill of } \\
\text { lading to Customs through the digital platform }\end{array}$ & Communication & Digital \\
\hline D6 & $\begin{array}{l}\text { Customs must review, verification and validation documents } \\
\text { submitted by importer }\end{array}$ & Control & Digital \\
\hline D7 & $\begin{array}{l}\text { Customs must send review and verification report to importer } \\
\text { through the digital platform }\end{array}$ & Communication & Digital \\
\hline D8 & An import must pay import duties at the bank & Substantive & Physical \\
\hline D9 & The bank must notify Customs through the digital platform & Communication & Digital \\
\hline D10 & Customs officials must physically examine consignment & Control & Physical \\
\hline D11 & Consignment must be released electronically after examination & Control & Digital \\
\hline
\end{tabular}

\subsection{Evolution of Norms from TBE to DBE}

To address the research purpose, this section presents the evolution of norms when a DBE emerge from a TBE. Norms T1, T2, and T3 in Table 1 on physical purchase, submission and notification of import valuation under the TBE continued as D1, D2, and D3 in Table 2 under the emerged DBE. The reason for the continuance is that the law that required submission of physical forms has not yet been revised to enable submission of electronic documents. Norms T8 and D8 on payment of import duties in Tables 1 and 2 respectively also did not evolve. The reason for their continuance is the unavailability of a national electronic payment system in Ghana. Under both the TBE and the emerged DBE, norms T10 and D10 in Tables 1 and 2 respectively on physical examination of consignment also did not evolve. The reason for their continuance is to check the deliberate act of importers to under-declare value of goods in order to pay less import duties.

However, norms T4 and T5 in Table 1 on physical purchase and submission of Customs import declaration forms under the TBE evolved into D4 and D5 in Table 2 where importers were now required to log into the digital platform, complete and submit Customs import declaration forms as well as other supporting documents. In the same vein, norms T6 and T7 in Table 1 on physical review and verification of import documents under the TBE as well as sending review report to the importer also evolved into D6 and D7 in Table 2 respectively where these norms are now carried out on the digital platform. As such, Customs officials use the digital platform to electronically review, verify and validate import related documents and also send review reports to the importers digitally. Norm T9 in Table 1 on physical notification of Customs of duty payments under the TBE evolved to D9 in Table 2 under the emerged DBE. As such, banks were now required to send digital payment notifications to Customs. Under the TBE, norm T11 in Table 1 on physical release of consignment evolved into norm D11 in Table 2 under the emerged DBE where after physical examination, the consignment is released digitally to end the import process.

Comparing the evolving of the behavioural norms following the emergence of the DBE from the TBE, it was evident that most communication norms have easily evolved from informal and formal to technical norms. On the other hand, substantive and 
control norms required more restructuring such as change in legislation as well as development of national information and communication technology infrastructure to enable transition from the physical to the digital domain.

\section{Conclusion and Future Works}

The aim of the study was to analyse which norms evolved and which ones remained as well as the reasons for the changes. This study points out that as TBEs evolve to DBEs so will their norms. This study reemphasizes that all norm types may evolve during the transition. However, communication norms are the easiest to digitize during the transition from TBE to DBE. This study also acknowledges the importance of a nation electronic payment systems and technology infrastructure as well as appropriate legislation in developing country context to facilitate the transition of norms. These knowledge facilitate better understanding and reconfiguration of norms when DBEs emerge from TBEs. Again, this knowledge provides practitioners with understanding of norms that can or cannot be migrated to digital domains and the factors that can constrain the transition to DBE. However, one key consequence of the evolving of norms from TBE to DBE is the issue of availability of the digital platform. Future research call is made to consider the conceptualization and actuality of norms in DBEs. We also call for further studies from the developed world perspective and other digital ecosystems to understand how contextual factors shape norm evolution in TBE to DBE transition.

\section{References}

1. Iansiti, M., Levien, R.: Strategy as ecology. Harvard Bus. Rev. 82(3), 1-14 (2004)

2. Nachira, F., et al.: A network of digital business ecosystems for Europe: roots, processes and perspectives. In: Proceedings of Digital Business Ecosystem. European Commission Information Society and Media (2007)

3. Stamper, R., et al.: Understanding the roles of signs and norms in organizations - a semiotic approach to information systems design. J. Behav. Inf. Technol. 19(1), 15-27 (2000)

4. Adner, R.: Match your innovation strategy to your innovation ecosystem. Harvard Bus. Rev. 84(4), 98-107 (2006)

5. Ceccagnoli, M., et al.: Cocreation of value in a platform ecosystem: the case of enterprise software. MIS Q. 36(1), 263-290 (2012)

6. Li, Y.: The technological roadmap of Cisco's business ecosystem. Technovation 29, 379-386 (2009)

7. Moore, J.F.: Predators and prey: a new ecology of competition. Harvard Bus. Rev. 71(3), 75-83 (1993)

8. Razavi, A.R., et al.: From business ecosystems towards digital business ecosystems. In: Proceedings of the 4th IEEE International Conference on Digital Ecosystems and Technologies, pp. 290-295 (2010)

9. Tsatsou, P., et al.: Towards a taxonomy for regulatory issues in a digital business ecosystem in the EU. J. Inf. Technol. 25, 288-307 (2010)

10. Liu, K.: Semiotics in Information Systems Engineering. Cambridge University Press, Cambridge (2000)

11. Effah, J.: Virtual process control modelling in organisational semiotics: a case of higher education admission. In: Liu, K., Nakata, K., Li, W., Galarreta, D. (eds.) ICISO 2015. IFIP AICT, vol. 449, pp. 51-59. Springer, Heidelberg (2015) 